\title{
Measurement System Incompatibility
}

National Cancer Institute

\section{Source}

National Cancer Institute. Measurement System Incompatibility. NCI Thesaurus. Code C63040.

Problem associated with the incompatibility of the measurement systems between and/or within device systems that are inherent to the individual device thereby leading to miscalculated or mismatched measurements from those devices, e.g., international metric system versus U.S. measurement system. 